3. The ether-extractable acids were separated into solid and liquid acid fractions, converted into methyl esters and fractionally distilled. The light petroleum-insoluble compounds were separated from the fractions. Analyses of the acids are given (Table 2): these show that the increases after cholesterol feeding occur in the solid, liquid and light petroleum-insoluble fractions.

4. The methyl esters of the light petroleuminsoluble esters were chromatographed and gave a number of fractions, some of which are probably ketonic bile acids (Table 4).

We are indebted to the Medical Research Council for a personal grant (to D.C.E.) and a grant for expenses.

\section{REFERENCES}

Bergström, S. (1952). Aarsskr. Lab. Landøkon. Forsøk., Kbh. 22, no. 16.
Bloch, K., Berg, B. N. \& Rittenberg, D. (1943). J. biol. Chem. 149, 511.

Byers, S. O. \& Biggs, M. W. (1952). Arch. Biochem. Biophys. 39, 301.

Cook, R. P. (1938). Biochem. J. 32, 1191.

Cook, R. P. \& Edwards, D. C. (1952). Abstr. 2nd Int. Congr. Biochem. Paris, p. 122.

Cook, R. P., Edwards, D. C., Riddell, C. \& Thomson, R. 0. (1955). Biochem. J. 61, 676.

Cook, R.P., Polgar, N. \& Thomson, R. O.(1950). Biochem.J. 47, 600 .

Edwards, D. C. \& Cook, R. P. (1951). Biochem. J. 48, ix.

Friedmann, T. E. (1938). J. biol. Chem. 123, 161

Haslewood, G. A. D. (1943). Biochem. J. 37, 109.

Hilditch, T. P. (1949). The Chemical Constitution of Fats, 2nd ed. London: Chapman and Hall.

Hilditch, T. P., Morton, R. A. \& Riley, J. P. (1945). Analyst, 70, 67.

Riddell, C. \& Cook, R. P. (1955). Biochem. J. 61, 657.

Siperstein, M. D. \& Chaikoff, I. L. (1952). J. biol. Chem. 198, 93.

\title{
Cholesterol Metabolism
}

\section{THE FATE OF INGESTED CHOLESTEROL IN THE INTACT RAT}

\author{
By R. P. COOK, D. C. EDWARDS, CHRISTINE RIDDELL AND R. O. THOMSON \\ Department of Biochemistry, Queen's College, Dundee (University of St Andrews)
}

(Received 1 March 1955)

Some of the neutral and acidic products of the faecal excretion after the ingestion of cholesterol have been described (Riddell \& Cook, 1955; Edwards \& Cook, 1955). The object of this communication is to put the results of the several experiments on a comparable basis and to give a picture of the metabolism of cholesterol in the entire animal. The method used has been to feed large amounts of cholesterol to one group of animals and to keep a control group on a diet low in sterols. The difference between the two groups has been taken to indicate the changes undergone by the ingested cholesterol. Schoenheimer \& Breusch (1933) demonstrated that in mice there was a balance between cholesterol synthesis and destruction, and that on diets rich in cholesterol destruction exceeded synthesis. Using labelled cholesterol, this conclusion has been confirmed for other animal species (Gould, Taylor, Hagermann, Warner \& Campbell, 1953; Langdon \& Bloch, 1953). It can thus be considered that differences between the total sterol fed and that excreted represents the cholesterol metabolized, this term being used to include all processes occurring within the animal. The method lacks the finesse of experiments using isotopically labelled sterols but has the advantage that large amounts of material are available for study. In work of this nature the isolation of intermediates in the biological degradation of cholesterol is of importance as pointer to further experiments.

The greater part of the sterol metabolic products appears in the gut and is excreted in the faeces. Some slight excretion occurs in the urine and sebum, but for practical purposes these pathways may be neglected. In addition to the experiments in which animals were fed animal cake which has a high fibre content, some experiments were carried out on synthetic diets low in fibre to determine the amount and nature of the steamvolatile acids. A short account of this aspect of the study has been given (Thomson, 1951). Balance experiments on the rat after cholesterol ingestion show that the absorbed cholesterol is localized in the liver, and this organ has been made the subject of preliminary study. The rat has a welldeveloped tolerance for ingested cholesterol and is a good subject for the study of its metabolism.

\section{METHODS AND MATERIALS}

The diets having animal cake as basis have been described (Riddell \& Cook, 1955). In addition, two experiments were made with synthetic diets low in fibre content, with and without added fat, to determine the nature of the faecal 
volatile acids, no other investigations being made. These diets were similar to those described by Cook, Polgar \& Thomson (1950). Six male animals were used in each series in each separate experiment. The methods used for extraction of faeces, saponification, removal of unsaponifiable matter (UM) and recovery of acids are described (Riddell \& Cook, 1955; Edwards \& Cook, 1955).

Steam-volatile acids. Total steam-volatile acids were determined on the extracted soap solution by the method of Friedmann (1938). The individual acids were determined by chromatography (Moyle, Baldwin \& Scarisbrick, 1948). The silica gel used was prepared by the method of Gordon, Martin \& Synge (1943).

Livers. These were investigated only in the animals fed the animal cake diet. At the conclusion of an experiment the animals were decapitated and exsanguinated. The livers were removed, weighed, minced coasely and dried in vacuo at $100^{\circ}$. The dried livers were extracted first with ether and then with ethanol, and the extract was weighed. Samples were analysed by the methods described previously.

\section{RESULTS}

In Table 1 are given the diets fed, the duration of the experiments, the average aggregate weights of the animals during the course of the experiments, interesting feature is that the value $S-C$ for the faecal extracts is very similar to the total amount of cholesterol fed.

In Table 2 are given the values for the total amount of steam-volatile acids in the faecal extracts and for the percentage distribution of the various acids as determined by chromatography. The method used does not differentiate between the isomeric $\mathrm{C}_{4}$ and $\mathrm{C}_{5}$ acids. Values are also shown on a kg. body weight per day basis. Large amounts of volatile acids are present in the faecal extracts, when the fibre-containing animal-cake diets are fed. On these diets acetic and propionic acids predominate. When synthetic diets are fed, the total amount of volatile acids is considerably decreased. The administration of cholesterol on the low-fat animal-cake diet increases the production of total volatile acids and the increase is most marked with the acetic acid fraction. Administration of additional fat decreased the excretion of volatile acids to about half of that found with the low-fat diet, and there was no significant difference between the $C$ and $S$ series. On the synthetic low-fibre diets, the production of total volatile acids and of acetic

Table 1. Consumption of added cholesterol and amount of total faecal extract on various diets

Six animals in each group. $C$ series low sterol diet, $S$ series added sterol diet.

\begin{tabular}{|c|c|c|c|c|c|c|c|c|}
\hline \multirow[b]{2}{*}{$\begin{array}{c}\text { Expt. } \\
\text { no. }\end{array}$} & \multirow[b]{2}{*}{ Diet } & \multirow[b]{2}{*}{$\begin{array}{c}\text { Duration } \\
\text { (days) }\end{array}$} & \multirow[b]{2}{*}{ Series } & \multirow{2}{*}{$\begin{array}{c}\text { Average } \\
\text { aggregate } \\
\text { wt. of } \\
\text { animals } \\
\text { (g.) }\end{array}$} & \multicolumn{2}{|c|}{ Added sterol fed } & \multicolumn{2}{|c|}{ Total faecal extract } \\
\hline & & & & & (g.) & $\begin{array}{c}\text { (g./kg. } \\
\text { body } \\
\text { wt./day) }\end{array}$ & (g.) & $\begin{array}{c}\text { (g./kg. } \\
\text { body } \\
\text { wt./day) }\end{array}$ \\
\hline VII & Animal cake & 53 & $\begin{array}{l}C \\
S\end{array}$ & $\begin{array}{l}1951 \\
1720\end{array}$ & 137.0 & $\overline{1.49}$ & $\begin{array}{l}124 \\
263\end{array}$ & $\begin{array}{l}1 \cdot 20 \\
2 \cdot 86\end{array}$ \\
\hline XIII & Animal cake plus olive oil & 32 & $\begin{array}{l}C \\
S\end{array}$ & $\begin{array}{l}1664 \\
1654\end{array}$ & $\overline{50 \cdot 7}$ & $\overline{0.97}$ & $\begin{array}{r}58 \\
122\end{array}$ & $\begin{array}{l}1 \cdot 10 \\
2 \cdot 32\end{array}$ \\
\hline XIV & Animal cake plus olive oil & 28 & $\begin{array}{l}C \\
S\end{array}$ & $\begin{array}{l}1891 \\
2155\end{array}$ & $\overline{59 \cdot 0}$ & $\overline{0.98}$ & $\begin{array}{l}106 \\
167\end{array}$ & $\begin{array}{l}2 \cdot 00 \\
2 \cdot 78\end{array}$ \\
\hline XV & Synthetic (no fat) & 14 & $\begin{array}{l}C \\
S\end{array}$ & $\begin{array}{l}2349 \\
2347\end{array}$ & $\overline{29 \cdot 6}$ & $\overline{0.89}$ & $\begin{array}{l}14 \cdot 7 \\
43 \cdot 3\end{array}$ & $\begin{array}{l}0.45 \\
1 \cdot 32\end{array}$ \\
\hline XVI & Synthetic plus olive oil & 14 & $\begin{array}{l}C \\
S\end{array}$ & $\begin{array}{l}1368 \\
1596\end{array}$ & $\overline{16 \cdot 0}$ & $\overline{0.71}$ & $\begin{array}{l}10 \cdot 8 \\
24 \cdot 6\end{array}$ & $\begin{array}{l}0.56 \\
1 \cdot 10\end{array}$ \\
\hline
\end{tabular}

the amounts of added cholesterol fed and the weights of the total ether and ethanol extracts. Values have been calculated on a kg. body weight per day basis for the added cholesterol ingested and for the faecal lipid excreted.

The intake of food and hence of cholesterol was greatest on the low-fat animal-cake diet because of the lower calorific value of the food, but similar amounts of the other diets were eaten. More faecal extract was obtained with the $C$ series animals on the animal cake ration which contained fibre than was obtained with the animals on the synthetic diets. In Expt. XIV the $C$ series animals showed an unexplained high excretion of faecal lipid. An acid is of the same order on the low- and high-fat diets whether cholesterol is administered or not.

In Table 3 are given values for the livers of the animals on the animal-cake diets. The livers showed an increase in weight after cholesterol feeding which was most marked in those animals receiving added fat. On the fat-containing diets there were marked increases in the total amounts of unsaponifiable matter, sterol and ether-extractable acids after the feeding of cholesterol.

In Table 4 the total amounts of unsaponifiable matter and of digitonin-precipitable sterol recovered from the faeces and the livers of the animals fed the animal-cake diets are given for both $C$ and 
Table 2. Steam-volatile acids in faecal extracts

Total volatile acids and individual acids as \% of total volatile acids. Values are given also for the excretion of total volatile acids and acetic and propionic acids as $\mathrm{mg} . / \mathrm{kg}$. body wt./day. $C$, low sterol diets; $S$, added sterol diets.

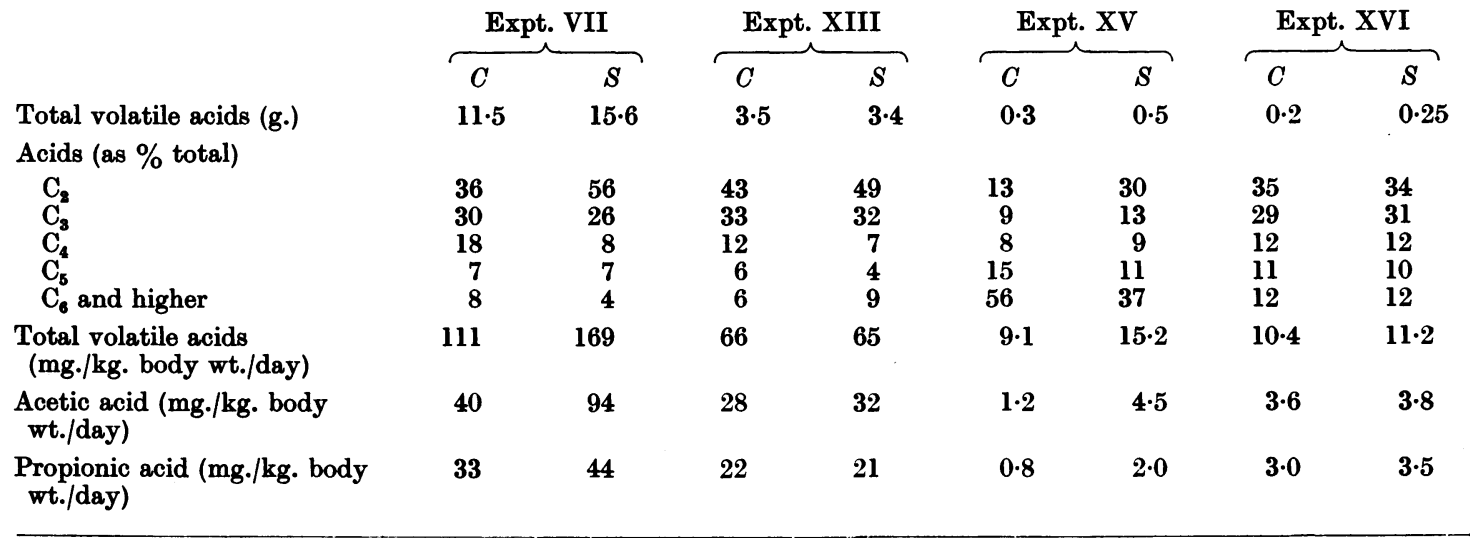

Table 3. Analysis of livers of animals on animal-cake diets

Values for fresh wt. as \% final body wt., lipid extract, unsaponifiable matter (UM), total sterol and ether-extractable acids are given. $C$, low sterol diets; $S$, added sterol diets.

\begin{tabular}{|c|c|c|c|c|c|c|}
\hline & \multicolumn{2}{|c|}{ Expt. VII } & \multicolumn{2}{|c|}{ Expt. XIII } & \multicolumn{2}{|c|}{ Expt. XIV } \\
\hline & $C$ & $S$ & $C$ & $S$ & $C$ & $S$ \\
\hline $\begin{array}{l}\text { Fresh wt. (g.) } \\
\text { As \% body wt. } \\
\text { Extract (g.) } \\
\text { UM (g.) } \\
\text { Sterol (g.) } \\
\text { Ether-extractable acids (g.) }\end{array}$ & $\begin{array}{c}81 \cdot 0 \\
3 \cdot 6 \\
4 \cdot 1 \\
0 \cdot 2 \\
0 \cdot 15 \\
2 \cdot 3\end{array}$ & $\begin{array}{l}88 \cdot 7 \\
4 \cdot 7 \\
3 \cdot 1 \\
0 \cdot 4 \\
0 \cdot 35 \\
1 \cdot 9\end{array}$ & $\begin{array}{r}70 \cdot 6 \\
3 \cdot 8 \\
5 \cdot 7 \\
0 \cdot 5 \\
0 \cdot 3 \\
3 \cdot 5\end{array}$ & $\begin{array}{r}\mathbf{9 3 \cdot 2} \\
\mathbf{4 \cdot 9} \\
\mathbf{1 4 \cdot 2} \\
\mathbf{4 \cdot 5} \\
3 \cdot \mathbf{4} \\
\mathbf{6 \cdot 4}\end{array}$ & $\begin{array}{r}75 \cdot 7 \\
3 \cdot 6 \\
4 \cdot 8 \\
0 \cdot 4 \\
0 \cdot 2 \\
2 \cdot 6\end{array}$ & $\begin{array}{r}90 \cdot 0 \\
3.9 \\
14 \cdot 2 \\
2 \cdot 8 \\
2 \cdot 4 \\
8 \cdot 7\end{array}$ \\
\hline
\end{tabular}

Table 4. Unsaponifiable matter (UM) and total digitonin-precipitable sterol excreted in faeces and obtained from the livers

Values are also given for saturated sterols, light petroleum-insoluble and -soluble acids and for the oleic acid equivalent of the ester sterol excreted in the faeces. $C$, low sterol diets; $S$, added sterol diets.

UM excreted + in livers (g.)

Sterol excreted + in livers (g.)

Saturated sterols excreted (g.)

Light petroleum-soluble acids excreted (g.)

Oleic acid equivalent of sterol esters excreted (g.)

Light petroleum-insoluble acids excreted (g.)

\begin{tabular}{|c|c|}
\hline \multicolumn{2}{|c|}{ Expt. VII } \\
\hline$C$ & $\boldsymbol{S}$ \\
\hline $18 \cdot 2$ & $135 \cdot 2$ \\
\hline $11 \cdot 6$ & $122 \cdot 8$ \\
\hline $9 \cdot 2$ & $40 \cdot 4$ \\
\hline $58 \cdot 2$ & 66.5 \\
\hline $\mathbf{3} \cdot 0$ & $8 \cdot 2$ \\
\hline 13.9 & $21 \cdot 2$ \\
\hline
\end{tabular}

$S$ series. Values are also given for the amounts of saturated sterol excreted, total light petroleumsoluble acids excreted and the oleic acid equivalent of the sterol esters excreted. These values have been calculated from the ester values given by Edwards \& Cook (1955), oleic acid being chosen as a typical ester-forming fatty acid. The total amounts of light petroleum-insoluble acids are also shown.

These experiments are compared further in Table 5, in which the results of the balance studies have been calculated on a comparable basis, i.e. per kg. body weight/day and percentage of ingested cholesterol. The mean of the values for the two experiments on the high-fat diet has been taken.

On both a high-and on a low-fat diet a large part of the sterol was excreted as unsaponifiable matter or as sterol. An approximate value of the percentage of unabsorbed sterol is obtained by taking the difference between the total digitonin-precipitable sterol excreted and the value obtained for saturated sterols. On the low-fat diet the unabsorbed cholesterol was $59 \%$, but on the fatcontaining diet it was $32 \%$. The absorptions (as 


\section{Table 5. Comparison of sterol and acid excretion on high-and low-fat diets}

The values for sterol and acid excretion given as $\mathrm{g} . / \mathrm{kg}$. body wt./day and as $\%$ of sterol fed and refer to $S-C$ series in each expt. In the case of the high-fat diet the values are the mean of Expt. XIII and XIV.

Total added sterol fed (A)

UM excreted + liver UM (B)

Digitonin-precipitable sterol excreted + liver sterols (C)

Digitonin-precipitable saturated sterols excreted (D)

Unsaturated sterol in faeces and livers (C-D)

Sterol converted into UM not precipitable by digitonin (B - C)

Sterol unaccounted for as UM (A - B)

Total light petroleum-soluble acids (E)

Oleic acid equivalent of esters excreted (F)

Light petroleum-soluble acids (E - F)

Light petroleum-insoluble acids

\begin{tabular}{|c|c|}
\hline \multicolumn{2}{|c|}{$\begin{array}{l}\text { Expt. VII. } \\
\text { Low-fat diet }\end{array}$} \\
\hline $\begin{array}{c}\text { (g./kg. body } \\
\text { wt./day) }\end{array}$ & $(\%)$ \\
\hline 1.49 & 100 \\
\hline $1 \cdot 29$ & 86 \\
\hline $1 \cdot 23$ & 82 \\
\hline $0 \cdot 35$ & 23 \\
\hline 0.88 & 59 \\
\hline 0.06 & 4 \\
\hline $0 \cdot 20$ & 13 \\
\hline $0 \cdot 15$ & - \\
\hline 0.06 & - \\
\hline 0.09 & 6 \\
\hline 0.09 & 6 \\
\hline
\end{tabular}

g./kg. body wt./day) were $\mathbf{0 . 2 6}$ on the low-fat diet and on the fat-containing diets $0 \cdot 48$. This fact is reflected in the higher levels of sterols obtained from the livers of the animals fed fat (Table 3).

Some of the unsaponifiable matter cannot be accounted for as digitonin-precipitable sterol. This amounted to $4 \%$ on the low-fat diet, but it was $21 \%$ on the fat-containing diet. This fraction is apparently accountable for as hydrocarbons, ketones and $3 \alpha$-stanols (cf. Riddell \& Cook, 1955).

There was a large increase in ether-soluble acids, particularly on the fat-containing diets. Some of this increase was due to an increase in the excretion of esterified cholesterol but, even if the oleic acid equivalent of the esters is deducted, a substantial percentage still remains unaccounted for. The light petroleum-insoluble acids on both types of diets account for about $7 \%$ of the ingested cholesterol. The total of the unsaponifiable matter, which is not accounted for, is of the same order as the sum of the light petroleum-insoluble acids plus the light petroleum-soluble acid fraction corrected for esterified acid. Thus in Expt. VII these values (as $\%)$ total 12 and 13 respectively and with the fatcontaining diets 30 and 29 respectively.

If the amounts of unsaturated sterol in the faeces and in the livers (i.e. C-D) and which may be regarded as unaltered cholesterol are deducted from the sterol fed, it is possible to obtain a picture of the cholesterol metabolized (or changed), i.e. $A-(C-D)$, values for the low-fat diet being given first. Given as percentage values of $A-(C-D)$ these are: converted into saturated sterol 56, 27; absorbed 43, 73; converted into unsaponifiable matter, not precipitable by digitonin 11,31 ; converted into light petroleum-soluble acids 16, 31; converted intolight petroleum-insoluble acids 14, 12. More saturated sterols are produced on the low-fat diet, but the absorption is greater, when added fat is present in the diet. On the added-fat diet there is a greater production of neutral matter, not precipitable by digitonin, and of light petroleumsoluble acids. The light petroleum-insoluble acids produced are of the same order with both diets.

\section{DISCUSSION}

The results give a general picture of the changes undergone by cholesterol in the intact rat on diets containing small and large amounts of fat. The complexity of the picture is added to by the presence of the normal microbial inhabitants of the gut. These bring about changes in the cholesterol itself, and in the products excreted in the bile and by the intestinal mucosa. Our experiments allow us only to surmise what these transformations are, but they are of undoubted importance. It has been shown that active metabolism of cholesterol occurs with cultures of intestinal bacteria developed under special conditions (Wainfan, Henkin, Rittenberg \& Marx, 1954).

The neutral fraction forms a large percentage of the excreted faecal material. This consists of unabsorbed cholesterol, saturated sterols of which coprostanol forms the greatest part and compounds not precipitable by digitonin (Riddell \& Cook, 1955). The site of conversion into coprostanol is considered to be the intestine and the mechanism that of microbial action. The large amount of saturated sterol formed on the low-fat diet, where absorption is smaller, is evidence for intestinal transformation. A good study of the mechanism of coprostanol formation has been made by Rosenfeld, Fukushima, Hellman \& Gallagher (1954). The other components of the neutral fraction are described by Riddell \& Cook.

The increased excretion of acids after cholesterol feeding is of great interest. The light petroleum- 
insoluble acid fraction contains a large amount of what are probably ketonic bile acids (cf. Edwards \& Cook, 1955). The main acid excreted in the bile of rats is cholic acid, and Bergström (1954) has shown clearly that this is derived from cholesterol. The process of conversion is complex and intermediates such as lithocholic and chenodeoxycholic acids are formed (Siperstein, Harold, Chaikoff \& Dauben, 1954). These acids are changed into keto acids and possibly hydroxylated by intestinal micro-organisms (Schmidt \& Hughes, 1942; Schmidt, Hughes, Green \& Cooper, 1942; Bergström \& Norman, 1953).

The experiments show that there is a greater excretion of steam-volatile acids, particularly acetic and propionic acids, on the fibre-containing diets than there is on the low-fibre or synthetic diets. The addition of cholesterol caused a significant rise only when the low-fat fibre-containing diet was fed, the addition of fat abolishing this effect. The results are difficult to interpret, but the large production of volatile acids on the fibrecontaining diets is presumably due to the intestinal fermentation of cellulose which may be affected by the presence of cholesterol. Our data are not adequate to decide whether cholesterol is broken down, in part at least, to smaller fatty acid units, but the possibility should be considered. It has been shown in rats that part of chain-labelled $\left(\mathrm{C}_{28}\right)$ cholesterol is eliminated as $\mathrm{CO}_{2}$ (Chaikoff et al. 1952).

The light petroleum-soluble acids which consist of saturated and unsaturated fatty acids are markedly increased in amount after sterol feeding. Part of this increase may be ascribed to the excretion of cholesteryl esters which show an increase, particularly when fat is added to the diet. Moreover, it is known that cholesterol lowers the absorption of fat (Cook \& Thomson, 1951). When the light petroleum-soluble acids are corrected for the acid excreted as ester (calculated as oleic acid), there is an excess of acids unaccounted for. An apparent balance of this excess may be made with the missing cholesterol, and it is suggested that cholesterol is converted in part into acids which appear in the light petroleum-soluble fraction.

Robinson (1946) has suggested that cholesterol may be converted into a branched-chain acid. Branched-chain acids have been shown to have a wide distribution in animal tissues. Van Bruggen, Hutchens \& West (1951) showed that, when ${ }^{14} \mathrm{C}$ labelled cholesterol was administered to animals, it appeared in the fatty acid fraction of various tissues and at least $5 \%$ of the label was so recovered. Preliminary experiments indicate that branchedchain acids are present in the solid acid fraction of the faecal acids. The site of transformation is un- certain, but the liver shows a rise in total acids after sterol feeding and it rapidly metabolizes cholesterol. Special methods are being developed for the study of cholesterol metabolism in this organ and in the intestine.

Our experiments give rise to numerous conjectures as to the pathways of cholesterol degradation in the organism, but their demonstration must await further experiment.

\section{SUMMARY}

1. The faecal excretion of lipid and the deposition of lipid in the livers of rats fed diets containing cholesterol without and with added fat has been investigated.

2. The total steam-volatile acids and their components formed on low- and on high-fibre containing diets were studied (Table 2).

3. The livers were analysed for unsaponifiable matter, sterol and ether-extractable acids (Table 3).

4. From a balance of the total amounts ingested and excreted (Table 4), the values for sterol and acid excretion are calculated per kg. body wt. and as a percentage of ingested cholesterol (Table 5).

5. More cholesterol is absorbed when added fat is present in the diet, but the conversion into saturated sterols is greater on the low-fat diet. The conversion of cholesterol into non-digitonin precipitableneutral compounds and into acids soluble in light petroleum is greater on the added fat diet. The conversion into light petroleum-insoluble acids which are mainly ketonic bile acids is of the same order with both diets.

We are indebted to the Medical Research Council for personal grants to D.C.E., C.R. and R.O.T. and also a grant for expenses. Part of the expenses were borne by a grant from the Scottish Hospital Endowment Research Trust.

\section{REFERENCES}

Bergström, S. (1954). Problem of Lipids. Int. Conf. Biochem. Brussels, p. 240.

Bergström, S. \& Norman, A. (1953). Proc. Soc. exp. Biol., N.Y., 83, 71.

Chaikoff, I. L., Siperstein, M. D., Dauben, W. G., Bradlow, H. L., Estham, J. F., Tomkins, G. M., Meier, J. R., Chen, R. W., Hotta, S. \& Srere, P. A. (1952). J. biol. Chem. 194, 413.

Cook, R.P., Polgar, N. \& Thomson, R. O.(1950). Biochem.J. 47, 600 .

Cook, R. P. \& Thomson, R. O. (1951). Quart. J. exp. Physiol. 36, 61.

Edwards, D. C. \& Cook, R. P. (1955). Biochem. J. 61, 671. Friedmann, T. E. (1938). J. biol. Chem. 123, 161.

Gordon, A. H., Martin, A. J. P. \& Synge, R. L. M. (1943). Biochem. J. 37, 79. 
Gould, R. G., Taylor, C. B., Hagermann, J. S., Warner, I. \& Campbell, D. J. (1953). J. biol. Chem. 201, 519.

Langdon, R. G. \& Bloch, K. (1953). J. biol. Chem. 202, 77. Moyle, V., Baldwin, E. \& Scarisbrick, R. (1948). Biochem. J. 43, 308.

Riddell, C. \& Cook, R. P. (1955). Biochem. J. 61, 657.

Robinson, R. (1946). Proc. Roy. Soc. A, 188, 143.

Rosenfeld, R. S., Fukushima, D. K., Hellman, L. \& Gallagher, T. F. (1954). J. biol. Chem. 211, 301.

Schmidt, L. H. \& Hughes, H. B. (1942). J. biol. Chem. 143, 771.
Schmidt, L. H., Hughes, H. B., Green, M. H. \& Cooper, E. (1942). J. biol. Chem. 145, 229.

Schoenheimer, R. \& Breusch, F. (1933). J. biol. Chem. 103, 439.

Siperstein, M. D., Harold, F. M., Chaikoff, I. L. \& Dauben, W. G. (1954). J. biol. Chem. 210, 181.

Thomson, R. O. (1951). Biochem. J. 48, ix.

Van Bruggen, J. T., Hutchens, T. T. \& West, E. S. (1951). Fed. Proc. 10, 263.

Wainfan, E., Henkin, G., Rittenberg, S. C. \& Marx, W. (1954). J. biol. Chem. 207, 843.

\title{
The Use of Polarography in the Examination of Ketosteroids Related to Cholesterol
}

\author{
By D. M. ROBERTSON \\ Department of Biochemistry, Queen's College, Dundee (University of St Andrews)
}

(Received 1 March 1955)

Wolfe, Hershberg \& Fieser (1940) were pioneers in the polarography of ketosteroids in body fluids by introducing a method for determining 17-ketosteroids in urine. Morris and his co-workers have made valuable contributions in this field culminating in a neat method, combining partition chromatography and polarography, for the examination of corticosteroids in human blood (Morris \& Williams 1953). In all these methods direct or classical polarography was used. Derivative technique was introduced by Heyrovsky (1946) with a circuit modified to produced a sharp peak in a polarogram instead of a stepped wave. A derived polarogram differs from the conventional type in that the rate of change $(\mathbf{d} i / \mathbf{d} E)$ of diffusion current $(i)$ with applied potential $(E)$ is measured instead of the diffusion current itself. The result is a peak, representing maximum $\mathrm{d} i / \mathrm{d} E$ occurring at or very near the half-wave potential of the conventional polarogram. This results in an improved definition of the value of the half-wave potential. In favourable cases, the height of the derived wave is proportional to the concentration of reacting material. The method used here embodied a more convenient circuit described by Leveque \& Roth (1949).

The technique of derivative polarography has been applied to the examination of $\mathrm{C}_{27}$-ketosteroids. The ketonic fraction from the neutral matter of the faecal extracts of animals fed large and small amounts of added cholesterol was investigated (see Riddell \& Cook, 1955). In addition, a number of ketonic bile acids and other ketosteroids have been studied. The work of Prelog \& Häfliger (1949) on the polarography of cyclohexanone formed a valuable source of reference.

\section{METHODS AND MATERIALS}

Apparatus. A Tinsley Three-Unit Ink Recording Polarograph was used in conjunction with a Tinsley Derivative Unit. Two Muirhead Decade Resistance Boxes were introduced into the potentiometer circuit, one at each end of the auto-dial wire. By this means recordings could be restricted to selected voltage ranges and the rate of voltage application could be decreased. A switch was used to eliminate the positive part of the potentiometer winding when it was desired to use the resistance boxes. The principle of these alterations is shown in Fig. 1. A dip type, saturated calomel electrode, with connexion through agar, was used. The dimensions are not critical.

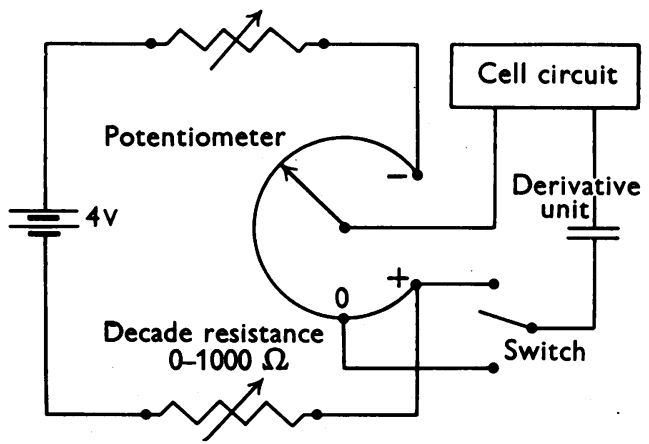

Fig. 1. Alterations to the polarograph potentiometer circuit.

All measurements were made with the polarographic cell immersed in a thermostatically controlled bath at $25^{\circ} \pm 0 \cdot 2^{\circ}$. A dropping mercury electrode was used having the characteristics of $1.54 \mathrm{sec}$. for the drop time $(t)$ and 